\title{
Comprehensive Evaluation of University Teachers: Using Entropy Method
}

\author{
Jian Rong, Qiang Sun* \\ Business School, Shandong University of Technology, Zibo, Shandong Province, China.
}

How to cite this paper: Jian Rong, Qiang Sun. (2021) Comprehensive Evaluation of University Teachers: Using Entropy Method. Journal of Humanities, Arts and Social Science, 5(2), 263-268.

DOI: $10.26855 /$ jhass.2021.07.010

Received: August 28, 2021

Accepted: September 25, 2021

Published: October 25, 2021

*Corresponding author: Qiang Sun, Business School, Shandong University of Technology, Zibo, Shandong Province, China.

Email: yssunqiang@163.com

\begin{abstract}
As an important part of university management and the basis of performance system, university teacher evaluation has become a research hotspot recently. However, there exist many questions in this area such as excessive subjectivity, inundate formalism and so on. All of this does not suit to the development of existing situation. Starting with the professional features of university teacher and considering the overall developing aims of university the paper design HR indexes evaluation system of university teachers from four aspects: basic quality, teaching capacity, scientific achievements and develop potential. And using information entropy-weighted method the paper constructs a human resources evaluation model of university teacher. According to the comprehensive testing coefficient we can get quantitative conclusion clearly which indicates each teacher's HR condition. Lastly combining with the demonstration of HR evaluation of management school teachers belonging to one certain university we validate the practicability and reliability of the evaluation model. The construction of evaluation model can not only help school managers evaluate teachers, but also help teachers take this as a benchmark, constantly study and explore, improve their comprehensive ability, and become excellent teachers with high quality and strong teaching and scientific research ability.
\end{abstract}

\section{Keywords}

Information entropy-weighted method, HR evaluation, Indexes evaluation system, University teachers

\section{Introduction}

On March 5, 2021, in the government's work report, Premier of the State Council Li Keqiang pointed out strategies of developing country through science and education and strengthening China through talents should be put into practice comprehensively. So it has come to an agreement that human resource should be the first resource in all organizations. And how to make universities which were charged with mission of educating human resources for our country developing constantly, healthily, harmonically and speedily has become the concerned focus of all respects. To this question, the most valid approach was to construct high-quality teacher teams which meant educating, attracting and rightly using talents by all means. Meanwhile, one important task of teacher team construction was teachers' human resources evaluation.

As the basic work of universities' human resources, teachers' human resources evaluation provided important 
evidence for teachers' compensation ascertain, duties promotion, recruitment and demission. Also, it was the key ache to fulfill the performance related pay system effectively (Chen, 2018). So how to construct scientific and reasonable HR evaluate indexes system to obtain evaluating conclusion objectively, comprehensively and accurately has turned into one problem to be researched deeply at present for the HR management of all universities.

Some countries of the West began the exploration of university teachers' HR evaluation system construction from the beginning of twentieth century. Roughly, its development experienced three stages. Firstly, from the 1960s to the end of 1980s appeared teachers' effectiveness evaluation which paid close attention to students' studying results. It concerned each segment of the teaching process. So it was one final evaluation. Secondly, after 1980s teachers' developmental evaluation which concerned teachers' professional development has grown up. The thirdly stage occurred after the middle and late stage of 1980s appeared specialized evaluation which concerned more of teachers' potential (Hou et al., 2018). Presently has formed more mature teacher evaluation system such as teachers' performance evaluation, teachers' developing potential evaluation, rewards and penalties evaluation and so on.

In china, HR evaluation of university teachers currently in effect generally adopted four dimension patterns: moral, capability, diligence and achievement. This pattern mainly focused work of teaching and scientific research, stressed the examination of teachers' actual final performance. But as lacking teachers' check of normal times and mainly depended on the determination of year end which took ways of voting and grading, this pattern existed many disadvantages such as excessive subjectivity and inundate formalism.

This paper started with the professional features of university teacher, designed HR indexes evaluation system of university teachers from four aspects: basic quality, teaching capacity, scientific achievements and develop potential. And using information entropy-weighted method, the paper obtained the weight of each index objectively. According to the comprehensive testing coefficient, we could get quantitative conclusion clearly which indicated each teacher's HR condition.

\section{Construction of HR Evaluation Model for University Teachers}

\subsection{Evaluating indexes system designing}

All universities took on three missions which were teaching, scientific research and social work. So the quality of higher education influenced the quality of talents cultivation directly (Chen, 2014). Also, the developing level and social class of the university mainly lay on many aspects of its teacher team such as its quantity, quality, stuff and social influence (Zhu, 2016). But the business of university teacher has the professional characters of high training cost, intense brainwork, difficultly measuring fruits, greater professional developing potential and so on. So as the organization of corporations the HR evaluating indexes system construction of university would be more complicated. In line with the principles of systematicness, concision, maneuverability (Liu, 2007), this paper chose 16 evaluating indexes from 4 aspects which were basic quality, teaching capacity, scientific achievements and develop potential combined with the overall developing aims of university and professional characters of university teacher. After all of that, we could construct HR evaluating indexes system of university teacher, which is seen in Table 1.

Indexes below were of many kinds: some were objective kinds, some were subjective ones, also some indexes were combination of individual evaluating, experts evaluating and students evaluating. So it became more important to make evaluating indexes reflect evaluating results more exactly. Using the information entropy-weighted method, the paper obtained the weight of each index more objectively so as to avoid the evaluating results deviation came from subjective and uncertain factors.

\subsection{Graded standard setting}

By establishing graded standard we could translate the qualitative indexes into quantitative ones. Supposed $B_{i j}$ was one index, $V=\left(v_{1}, v_{2}, v_{3}, v_{4}\right)$ showed HR evaluating standard gathers of university teachers, and the gather of

$\left(v_{1}, v_{2}, v_{3}, v_{4}\right)$ denoted (Excellent, Fine, Moderate, Poor). And then we could give mark to the evaluated teacher from 1 to 10 according the grade reference in Table 1. 
Table 1. HR evaluating indexes system of university teacher

\begin{tabular}{|c|c|c|c|}
\hline $1^{\text {st }}$-level index & $2^{\text {nd }}$-level index & Index meaning & Grade reference \\
\hline \multirow{4}{*}{ basic quality $B 1$} & Record and degree $B 11$ & final achieved record and degree & department records \\
\hline & Mind and body $B 12$ & physical quality and mental healthy & delphi method \\
\hline & Academic morality B13 & abidance of moral code in academic activities & delphi method \\
\hline & Teaching virtue $B 14$ & teacher's professional moral norm & questionnaire statistics \\
\hline \multirow{4}{*}{ teaching capacity $B 2$} & Teaching quantity B21 & amount of class teaching & dean's office statistics \\
\hline & Teaching quality B22 & students' evaluation and excellent rate of exam record & questionnaire statistics \\
\hline & $\begin{array}{l}\text { Teaching achievement } \\
\qquad \text { B23 }\end{array}$ & reward of teaching and students directing & dean's office statistics \\
\hline & Teaching research $B 24$ & courses construction and educational reform project & dean's office statistics \\
\hline \multirow{4}{*}{$\begin{array}{l}\text { scientific achieve- } \\
\text { ments B3 }\end{array}$} & $\begin{array}{l}\text { Paper and monograph } \\
\text { B31 }\end{array}$ & quantity of retrieval papers and monographs & $\begin{array}{c}\text { scientific department } \\
\text { statistics }\end{array}$ \\
\hline & Scientific project $B 32$ & amount of directing lateral and vertical projects & $\begin{array}{c}\text { scientific department } \\
\text { statistics }\end{array}$ \\
\hline & Scientific award B33 & awards amount of state, provincial and school level & $\begin{array}{c}\text { scientific department } \\
\text { statistics }\end{array}$ \\
\hline & Scientific funds $B 34$ & funds number of lateral and vertical projects & $\begin{array}{l}\text { scientific department } \\
\text { statistics }\end{array}$ \\
\hline \multirow{5}{*}{ develop potential B4 } & $\begin{array}{l}\text { Leaders' evaluation } \\
\qquad \text { B41 }\end{array}$ & opinions integration of many managers & delphi method \\
\hline & Advanced studies B42 & condition of advanced training & department records \\
\hline & Academic concurrent & concurrent post and involvement of domestic and & individual \\
\hline & post $B 43$ & International academic teams & demonstration \\
\hline & Social work $B 44$ & other duties in faculty or subject foundation & department records \\
\hline
\end{tabular}

\subsection{Sample evaluating matrix establishment}

Supposed there were $r$ evaluated teachers, and the sequence number was $k$ which from 1 to $r$. Also, there were $s$ evaluating indexes, sequence number was $l$ which from 1 to $s$. So the mark of the jth evaluated teacher of the ith index was $a_{i j}$, and we also could get the average mark of $a_{i j}$ which was $\bar{a}_{i j}$. From all of that, we could construct evaluating matrix of teachers' HR evaluating capacity $A$ as follows:

$$
A=\left(\begin{array}{ccc}
a_{11} & \ldots & a_{1 r} \\
\vdots & \ddots & \vdots \\
a_{s 1} & \cdots & a_{s r}
\end{array}\right)
$$

\subsection{Weight giving by information entropy-weighted method}

Supposed there were $m$ evaluating indexes and $n$ evaluated teachers which formed the original index matrix $X=\left(x_{i j}\right)_{m * n}$. To one sum index of $x_{i}$, the bigger value disparity of $x_{i j}$, the greater effect of the index in the evaluation. If the value of one $x_{i}$ sum equals, the index would have no effect to the evaluation.

In information theory, entropy was the measurement on the degree of system disorder. Its expression was as follows:

$$
H(x)=\sum_{j=1}^{n} p\left(x_{j}\right) \ln p\left(x_{j}\right)
$$

$x_{j}$ was the value of state(there were $n$ states); $p\left(x_{j}\right)$ was the probability of appearance the $j$ th state. 
From the index data matrix, it showed the more of the difference on one index value, the less of the information entropy, and the more information it supplied, also its weight should be greater; contrariwise, the less of the difference, the more of its information entropy, and the less of information it supplied also the less of its weight (Shannon, 1948). So by using information entropy, we could figure out the weight of indexes which would be the evidence of multi indexes evaluation according to the degree of difference on indexes.

The evaluating steps on entropy-weighted method were as follows:

(1) Quantified all indexes and calculated the weight of index value on the $j t h$ evaluated teacher which denoted as $P_{i j}$

$$
p_{i j}=x_{i j} / \sum_{j=1}^{n} x_{i j}
$$

(2) Calculated entropy value of the ith index which denoted as $e_{i}$

$$
e_{i}=-k \sum_{j=1}^{n} p_{i j} \ln p_{i j}
$$

$k>0$, supposed $k=1 / \operatorname{lnn}$, In denoted nature logarithm, $e_{i} \geq 0$, if $x_{i j}$ equaled when given all $j$, then $e_{i}$ reached the max, the index of $i$ had no effect, vice verse.

(3) Calculated the different factor of the index $i$ which denoted as $g_{i}$. For the given index $i$, the less different value of $x_{i j}$, the more of $e_{i}$; when $x_{i j}$ equaled, $e_{i}=e_{\max }=1$, and then the index of $i$ had no effect. And the more difference of the evaluated indexes, the less value of $e_{i}$, and the greater index to the compare of the evaluation. Also, we could define the vector of different factor as

$$
G=\left(g_{1}, g_{2}, \ldots, g_{m}\right) \text {, and } g_{i}=1-e_{i}
$$

In the vector the more value of $g_{i}$, the more important of the index (Sun, 2021).

(4) Ascertained evaluating weight of teachers' HR by using information entropy-weighted method which denoted as $w_{i}$,

$$
w_{i}=g_{i} / \sum_{i=1}^{m} g_{i}, \quad(i=1,2,3, \cdots, m)
$$

The weight vector $w=\left(w_{1}, w_{2}, \ldots, w_{m}\right)$ were composed of $m$ indexes.

\subsection{HR evaluating coefficient calculation}

$$
v_{j}=\sum_{i=1}^{m} w_{i} p_{i j}
$$

$v_{j}$ denoted as the evaluating value of the $j$ th evaluated teacher.

And ranking:

$$
v=\left(v_{j 1}, v_{j 2}, \cdots, v_{j n}\right)
$$

$v_{j 1}=\max v_{j}, v_{j n}=\min v_{j}$

So according to the final result we could make more clearly quantitative judgment to all teachers' HR evaluation.

\section{Demonstration Analysis of HR Evaluating Model for University Teachers}

There were 10 teachers in management school of one certain university. Using the means above, we could evaluate their HR capacity comprehensively. The mark of every teacher could be achieved by experts, and the index data matrix was seen in Table 2.

Here $n=10$, so we chose $k=1 / \ln 10$, according to (2) (3) and (4), we could achieve the weight of indexes: $W=$ $\left(w_{11}, w_{12}, w_{13}, w_{14}, w_{21}, \ldots, w_{44}\right)=(0.02,0.13,0.12,0.11,0.03,0.05,0.10,0.08,0.03,0.05,0.02,0.09,0.03,0.05,0.06,0.03)$

And so the $2^{\text {nd }}$ weight of indexes could be got: $w^{\prime}=\left(B_{1}, B_{2}, B_{3}, B_{4}\right)=(0.38,0.26,0.19,0.17)$

On the basis of forms (5) and (6), we could calculate the evaluated teacher's HR evaluating coefficient: $v=\left(v_{1}, v_{2}, v_{3}, \ldots, v_{10}\right)=(0.110,0113,0.099,0.091,0.098,0.082,0.097,0.105,0.112,0.092)$

After ranking, the final accounts were as follows:

$v^{\prime}=\left(v_{2}, v_{9}, v_{1}, v_{8}, v_{3}, v_{5}, v_{7}, v_{1}, v_{4}, v_{6}\right)=(0.113,0.112,0.110,0.105,0.099,0.098,0.097,0.092,0.091,0.082)$

From the final account, we could clearly see the quantitative rank of all evaluated teachers' HR capacity: the 2nd 
evaluated teacher achieved the highest mark of the evaluation, and the lowest mark of the evaluation was the 6th one. So from the final quantitative mark, we could say that the 2nd teacher's HR comprehensive capacity was the best.

Table 2. Teachers' HR evaluating experts score chart of management school

\begin{tabular}{ccccccccccc}
\hline & Te.1 & Te.2 & Te.3 & Te.4 & Te.5 & Te.6 & Te.7 & Te.8 & Te.9 & Te.10 \\
\hline Record and degree (B11) & 8 & 9 & 7 & 6 & 8 & 10 & 9 & 8 & 7 & 8 \\
\hline Mind and body (B12) & 9 & 10 & 5 & 7 & 6 & 8 & 7 & 9 & 6 & 8 \\
\hline Academic morality (B13) & 9 & 8 & 7 & 5 & 6 & 3 & 7 & 8 & 10 & 6 \\
\hline Teaching virtue (B14) & 8 & 9 & 8 & 10 & 7 & 6 & 8 & 9 & 7 & 5 \\
\hline Teaching quantity (B21) & 10 & 8 & 9 & 8 & 7 & 8 & 8 & 9 & 8 & 8 \\
\hline Teaching quality (B22) & 8 & 7 & 6 & 8 & 10 & 8 & 8 & 7 & 9 & 6 \\
\hline Teaching achievement (B23) & 8 & 9 & 6 & 5 & 10 & 7 & 8 & 5 & 6 & 6 \\
\hline Teaching research (B24) & 6 & 8 & 7 & 5 & 6 & 8 & 10 & 5 & 5 & 6 \\
\hline Paper and monograph (B31) & 9 & 8 & 10 & 9 & 6 & 7 & 8 & 9 & 9 & 10 \\
\hline Scientific project (B31) & 6 & 9 & 8 & 6 & 8 & 7 & 6 & 10 & 9 & 7 \\
\hline Scientific award (B33) & 9 & 8 & 6 & 7 & 8 & 6 & 9 & 10 & 6 & 7 \\
\hline Scientific funds (B34) & 6 & 5 & 7 & 7 & 6 & 7 & 6 & 10 & 5 & 7 \\
\hline Leaders' evaluation (B41) & 8 & 7 & 7 & 8 & 8 & 6 & 6 & 8 & 10 & 7 \\
\hline Advanced studies (B42) & 9 & 8 & 7 & 8 & 7 & 7 & 10 & 6 & 8 & 7 \\
\hline Academic concurrent post (B43) & 8 & 7 & 6 & 10 & 7 & 7 & 6 & 6 & 9 & 8 \\
\hline Social work (B44) & 6 & 10 & 7 & 7 & 8 & 6 & 6 & 7 & 8
\end{tabular}

\section{Conclusions}

By means of the HR evaluating model construction for university teachers and the applied demonstration for management school, one certain university above we could obtain the following conclusions:

(1) Compared with the traditional university teachers HR evaluating system which only concentrated in teaching and scientific research, we constructed new evaluating indexes system by means of putting in two aspects: basic quality and develop potential. Taking the professional features of university teacher into account sufficiently, we carried out many work of university teacher as enriching self knowledge constantly and increasing specialized skill into the HR evaluation. All of that could contribute to the achievement of university teachers' self developing object and also could consolidate that with university's strategic aim.

(2) In university teachers' HR evaluation, there were many indexes which were too subjective to measure. With use of quantitive research, we could avoid this shortcoming. And also could change the conditions that only judged educational fruit from school amount and only made HR evaluation for university teacher from teaching and scientific research. According to our quantitive conclusion, we could make evaluation more clearly and also could provide reference for other group in university such as assistants or office staff.

(3) With the use of information entropy-weighted method, we made weight for each index which avoided the influence from manmade subjective factors and the subjectivity of evaluation conclusion. Meanwhile, we combined the subjective weight with the value of entropy so as to form the comprehensive weight. All of that sufficiently considered all information came from objective indexes and subjective ones and took account of experts' opinions with objective statistical nature. So we could see advantages of this way: had more clear definition, had more simple calculation and had more scientific conclusion.

(4) From the applied demonstration of one certain university management school, we could see B1 (basic quality) occupied the most weight which achieved 38 percent and the second was B2 (teaching capacity) which occupied 26 percent. Also B3 (scientific achievements) occupied 19 percent weight, and B4 (develop potential) occupied 17 percent. With the meaning of entropy-weighted method, we could say the diversity of basic quality and teaching capacity were bigger among evaluated teachers and these two aspects should be taken more attentions of school managers.

(5) With the final evaluating coefficient which could be seen in testing conclusion, we had more clearly references to select or grade teachers. As in this example, we could consult the quantitive conclusion after ranking to promote some ones.

Compared with traditional evaluation way, this paper constructed indexes system quantitively with use of infor- 
mation entropy-weighted method to evaluate HR conditions of university teacher. Combined with objective and subjective factors the method could settle many questions of this evaluation such as multi factors, fuzziness and subjective judgment. Also, it could break through limitations of qualitative weighted indexes and make evaluating conclusions more scientifically and objectively. And all of our conclusions were hoped to provide references to the activities of university HR management carrying out.

\section{References}

Chen, M. L. (2018). Research on sustainable development of university teachers. Talents Exploitation.

Chen, Q. X. (2014). High-quality Teacher Teams Construction of University. Research on High-education of Heilongjiang.

Hou, M. M., Lin, Z. Y., Chen, J. N., et al. (2018). Optimization on the buried depth of subsurface drainage under greenhouse condition based on entropy evaluation method. Entropy.

Liu, C. F. (2007). HRM of Modern University Teachers. National Press.

Shannon, C. E. (1948). A mathematical theory of communication. Bell System Technical Journal.

Sun, X. S. (2021). Green city and regional environmental economic evaluation based on entropy method and GIS. Environmental Technology \& Innovation.

Zhu, X. T. (2016). Courses Barriers, learning barriers and construction of university courses. High-education of Jiangsu (in Chinese). 